\title{
Historical and topographical amnesia on the information highway: Metaphors and tacit knowledge
}

Leif Bloch Rasmussen and Gertrud Krarup

ProjectCentre CESAR, Copenhagen Business School, Copenhagen Science Park Symbion, DK-2100 Copenhagen Ø, Phone: + 45391798 66, Fax: + 4539179863

Email: iqlbr@cbs.dk,iqgk@cbs.dk

\begin{abstract}
The information highway and the information age are two concepts loaded with metaphorical connotations. They seem to imply the possibility for orientation in space and connection in history as the tacit knowledge of how people could and should be able to cope with the future.

A cognitive semantic exploration of the 'directive' metaphor of being on the information highway and the 'container' metaphor of being in the information age, however, both point to a tacit acceptance of a very limited knowledge of time and space. They indicate the cultural and democratic risks of creating topographical and historical amnesia.

As a movement away from the dangerous implications of using these metaphors, we search for orientation in space and connection in history from two great historical figures: Kierkegaard on historical understanding through choices in our personal life using his Stages on The Way of Life, and Goethe on spatial understanding in the eye using his colour theory (Farbenlehre).
\end{abstract}

\section{INTRODUCTION $^{1}$}

During the past few years, we have seen many reports on national information and communication technology (ICT) strategies from all over the world. They all seem to be alike and created from the same viewpoint and fundamental values: change is ongoing, it is global, it is fast and we all have to obey, participate, accept, and try to keep apace. 
It may be argued that these strategies are only examples of political decisions, without much impact on reality because the speed of technological development in the so-called free market is so fast that no one can and need control it. 'Remove the obstacles and don't brake' seems to be the credo for the industrialists and free riders in reengineering nations.

In this article, this credo will initially be confronted by departing from some speculations on our ability, or even inclination, to create the ultimate perception machine - the Perceptron - as envisioned by the French philosopher, Paul Virilio, and the American system philosopher, Charles West Churchman. Both Virilio and Churchman argue that, physically and mentally, we are losing some of our most fundamental categories and perceptions: time and space.

These two philosophers will set the scene for the metaphorical exploration of some of the national ICT strategies.

\section{TOPOGRAPHICAL AND HISTORICAL AMNESIA - PHYSICALLY}

In La Machine de Vision, Paul Virilio (1987) investigates how using computers may develop topographical and historical amnesia. One of the most important physical characteristics of this amnesia is the weakening of peripheral vision in favour of focal vision without context. This may in turn lead to 'lazy eyes' and, finally, blindness. Virilio sees this as a movement towards the giving up of human perception faculties in favour of the vision machine - the ultimate robot in the human being - the Perceptron. He states his main hypothesis this way:

'With the industrial proliferation of vision and audio-visual prostheses, with the excessive use of these means to instant transport of images from their tender beginning we will witness an ever increasing artificial coding of mental images with an ever decreasing time horizon to fix the images without much benefit afterwards - a fast collapsing of the mnemotechnical consolidation.

This seems natural if you, on the other hand, remember that sight and its spatio-temporal organization comes before movement, speech and their coordination. It does this through recognition and making recognizable and the ability to create mental images: thoughts and cognitive functions, which do not know passivity ${ }^{26}$ (Virilio, 1989, p. 22. Our translation from the Danish version).

By not consolidating images, our consciousness simply refuses to create and sustain the image. We lose our faculty for creating images and space orientation through the eyes.

Similarly, Churchman (1976) has warned against the ultimate stress put on the future in systems design (SD). He argues that, as systems designers, by the use of global computer-modelling and global computer networks, we forget and abandon the past and put too much belief in a computerized future. As he puts it:

"One often hears these days that global-systems simulations are only "first approximations," crude and wrong in many ways. But both Descartes and Paul realized that if you believe you have a "first approximation," then you also have an idea about the second, the third, and the "limit," else your "first" is not an "approximation" at all: "Now we see through a glass darkly, but then face to face. Now I know in part: then I shall understand fully..." To Paul, the 
"basic" aspects of mankind's progress lie in faith, hope and love. To Descartes, they lie in the proof of the existence of a benign Supreme Being. Most global simulators do not care to resort to such reactions to our past and indeed ignore them completely and without reflection. None of them seem to wish to forecast what society would be like in the year 2020 if mankind's faith, hope and love with respect to God were restored, although this may be the most important forecast of all. The philosophical point is that none of us who concern ourselves with SD have a sound basis for choosing between Paul and an MIT simulator' (Churchman, 1974, p. 460 - 461).

Both Virilio and Churchman point to the probability of the collapse of our physical understanding of the categories of time and space as we try to install computerized prostheses instead of our sense apparatus.

\section{TOPOGRAPHICAL AND HISTORICAL AMNESIA - MENTALLY}

However, this possibility of physical reduction, or even extermination of our senses, may be compensated through mental explorations and expansions or, literally speaking, through bigger brains and bigger minds. The information society and the so-called knowledge-based society may be compensating as we develop more abilities to use ICT without limits - spatially as well as temporally. This, at least, is the promise in what we have called the 'national' ICT strategies that we use as illustrations in this article.

Is there any indication in these strategies which may compensate for the physical deterioration of time and space? Or do they also accept and even provoke this deterioration conceptually? ? $^{3}$

\section{WAYS IN METAPHORICAL ANALYSIS}

In Rasmussen (1994, 1995, 1996), Holm-Pedersen and Rasmussen (1995), Krarup and Rasmussen (1996), eight different ways of designing inquiring systems based on eight world views (in German, Weltanschauung) have been identified, described, and documented. Churchman's term, inquiring system, is used as it is a more generic and well-founded epistemological term than information systems or even knowledge-based systems. This work is especially based on Jantsch (1975, 1979), Churchman $(1971,1982)$ and Singer $(1924,1948,1959)$.

These world views are the foundation for design methodologies; each methodology seems to make use of its own special metaphors and tacit knowledge. They are all related to the very different ways in which we imagine the information society: the way we are going to live and work on the information highway and in the information age.

The eight world views, design methodologies, and most frequently used metaphors in organizational design, are depicted in Table 1.

It is our contention that there will be much benefit from a more thorough investigation of the metaphors used in these world views and design methodologies and national reports, as this kind of investigation may reveal the hidden tacit knowledge we have to live and work by on the information highway 
and in the information age, if there is any at all. However, to our knowledge, there has been no such attempt to analyze the metaphors in the political manifestos of the information society (Krarup, 1994; Krarup and Rasmussen, 1996).

The attempt in this article is, however, much more modest. We aim to explore some of the possibilities in performing a thorough metaphorical analysis in finding the tacit knowledge behind three of the national strategies for creating the information society (those of the European Union, the United States, as well as the report from the European Round Table of Industrialists).

The hypothesis is that, even though such strategic manifestos seem to imply design for social and cultural benefits, they only make use of the first two of the eight world views and design methodologies: they are non-theoretical and/or positivistic in their world views and use trial-and error-doing and/or structured design in their design methodologies.

The hermeneutic 'proof' of this hypothetical pudding is not straightforward as the words used in the texts cannot be taken at their positive social and cultural face value. The tacit knowledge must be revealed. One way of doing this is through metaphorical analysis.

\section{METHODS IN METAPHORICAL ANALYSIS}

The importance of metaphors - and tacit knowledge - has primarily been discussed in linguistics, hermeneutics, and psychology. In these three disciplines, it has been acknowledged that metaphors and tacit knowledge play an important part of our daily, practical life. Lately, this knowledge seems to be part of a growing awareness of theories on language, communication, science, and society. At least four methods may be identified in metaphorical analysis:

The traditional method of metaphorical analysis parses the text for those words that, as metaphors, are an alternative and richer means of expression than the word in its literal use. Metaphor thus means transference from one domain to another. Typically, this transference takes the form of a figure of speech which replaces the real matter. In systems design and organizational theory (especially in literature and theories on organizational culture), systems design and futures research, some researchers have begun this kind of study (Morgan, 1986; Kendall and Kendall, 1993; Judge, 1993). This method is used in columns 2, 3 and 4 of Table 1.

The second method, cognitive semantics, challenges the above-mentioned method of analysis as based on the traditional western way of thinking. It accuses the method of being based on disembodied and abstract categories. Cognitive semantics confronts this view and looks for metaphors and image schemata which are embodied and concrete. Our perception is thus taken to be grounded in our body. The method may reveal tacit knowledge and hidden world views. This method is in accordance with Virilio, and is used in column 5 in Table 1.

The third method is based on theories of poetry and literature or, more generally speaking, philosophical theories of language and aesthetics. In its most radical form, the Danish philosopher K.E. Løgstrup claims that a metaphor may very well be defined as bringing two different words from different domains together, but that such a bringing together must bring some kind of radicalism and inventiveness along with it, or else it will turn out to be a pale and flat decoration. 


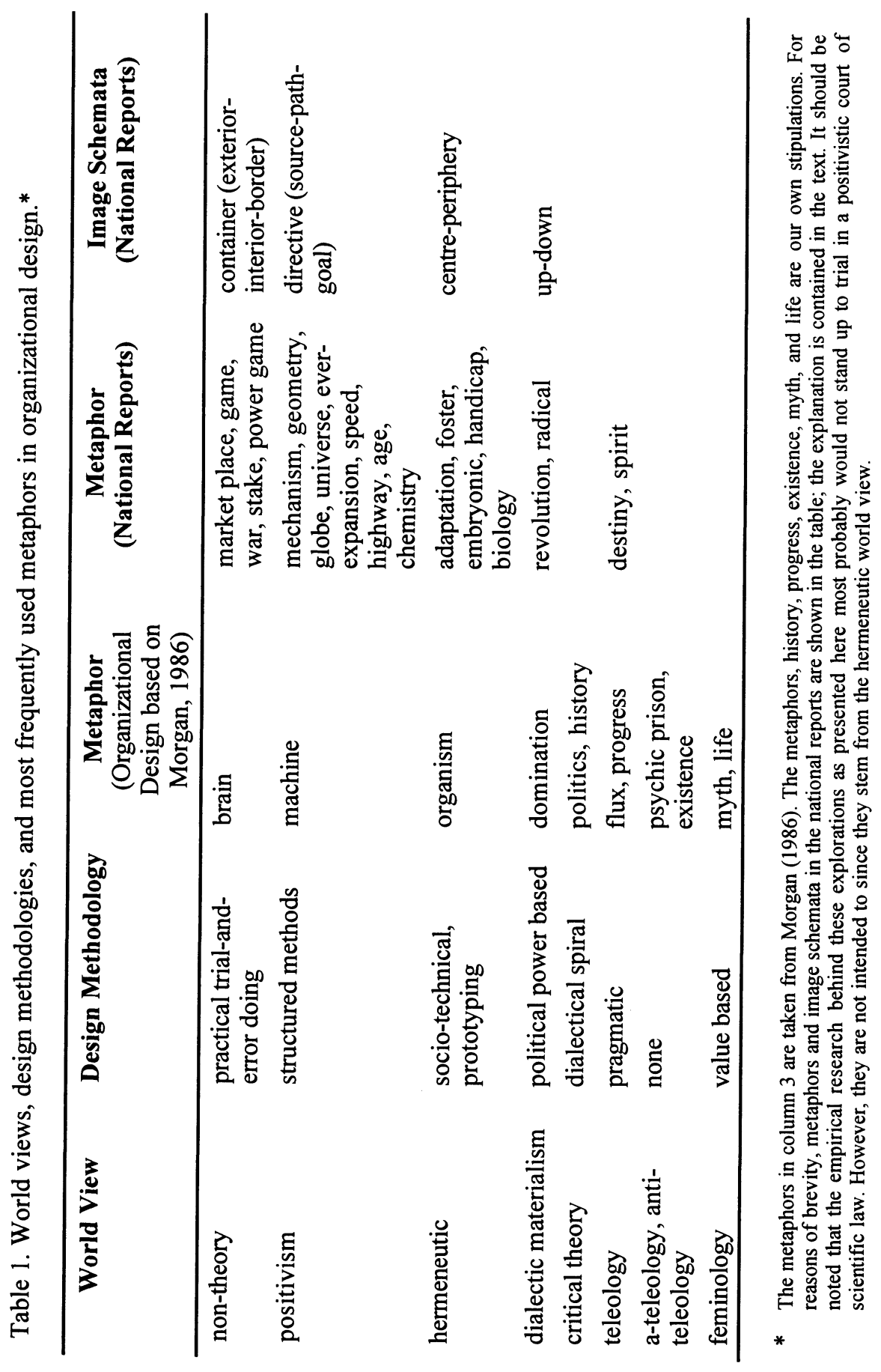


This method has been tried in the metaphorical analysis of the national strategies, but ended with only one possible metaphor: the American skyway. It is therefore not included in Table 1 as was originally intended.

Finally, the fourth method is political. It tells us that metaphors are political power instruments and that we are ruled by the political power idea: overrule and make obsolete a dead metaphor, and design a better one. Because metaphors are poetic speech, people will understand them (within their body), and obey. This hypothesis from the old theories of rhetoric is not used in the analysis even though, ironically enough, it is its main argument.

\section{METHOD ONE: TRADITIONAL WESTERN WORLD VIEW AND NATIONAL ICT STRATEGIES}

The traditional western world view seems to hold that reason may be depicted as follows:

'Reason is the mechanical manipulation of abstract symbols which are meaningless in themselves, but can be given meaning by virtue of their capacity to refer to things either in the actual world or in possible states of the world' (Lakoff, 1987, p. 7).

With the advent of the digital computer - and maybe even more so with the coming of neural networks - the hypothesis of reason and meaning as manipulation of strings of meaningless symbols seems to many computer scientists and system designers (through circular reasoning) to be the final proof that the mind works like a computer. This mind-as-computer idea is, of course, a metaphor, and it may be a dangerous one. It even elevates the brain to the equal of the mind.

Furthermore, it rests on the idea that there is a symbol-to-object correspondence independent of the human mind and body. The definition of meaning from these kinds of abstract symbols must therefore also be independent of the human mind and body.

The metaphors in column 2, 3 and 4 of Table 1 represent this method of metaphorical analysis of the three national strategies. Quite simply, we have identified all the words in these texts that communicate something other than their literal meanings.

Most of the metaphors are identified in the first three world views, and only 'revolution, radical' and 'destiny, spirit' belong to other world views. This is, of course, is not surprising. One would expect this on the political scene where the reports are written.

But, according to cognitive semantics, there may be tacit knowledge and hidden world views in the texts.

\section{METHOD TWO: COGNITIVE SEMANTICS' WORLD VIEW - IMAGE SCHEMATA}

Lakoff confronts the traditional western view:

'To question the classical view of categories in a fundamental way is thus to question the view of reason as disembodied symbol manipulation and 
correspondingly to question the most popular version of the mind-as-computer metaphor. Contemporary prototype theory does just that - through detailed empirical research in anthropology, linguistics, and psychology. The approach to prototype theory that we will be presenting here suggests that human categorization is essentially a matter of both human experience and imagination - of perception, motor activity, and culture on the one hand, and of metaphor, metonymy, and mental imaginary on the other. As a consequence, human reason crucially depends on the same factors, and therefore cannot be characterized merely in terms of the manipulation of abstract symbols' (Lakoff, 1987, p. 8).

Of course, some part of human reasoning may be abstract symbol manipulation, but this kind of argument from the cognitive sciences suggests that this is a very limited view and that we should see it as a special case of a much more general theory of cognitive models. But to change the very concept of categorization is to change our concept of the mind and our understanding of the world.

Lakoff's evidence suggests:

'... a shift from classical categories to prototype based categories defined by cognitive models. It is a change that implies other changes: changes in the concepts of truth, knowledge, meaning, rationality - even grammar.

Some of the ideas that will fall are:

- Meaning is based on truth and reference; it concerns the relationship between symbols and things in the world.

- Biological species are natural kinds, defined by common essential properties.

- The mind is separate from, and independent of, the body.

- Emotion has no conceptual content.

- Grammar is a matter of pure form.

- Reason is transcendental, in that it transcends - goes beyond - the way human beings, or any other kind of beings, happen to think. It concerns the inferential relationships among all possible concepts in this universe or any other. Mathematics is a form of transcendental reason.

- There is a correct, God's eye view of the world - a single correct way of understanding what is and is not true.

- All people think using the same conceptual system.

These ideas have been part of the superstructure of Western intellectual life for two thousand years. They are tied, in one way or another, to the classical concept of a category. When that concept is left behind, the others will be too. They need to be replaced by ideas that are not only more accurate, but more humane' (Lakoff, 1987, p. 11).

It is Lakoff's hypothesis that 'Image schemata structure both our conceptions and our rich mental images' (Lakoff, 1987, p. 453).

The fundamental position in cognitive semantics, as part of Lakoff's kind of cognitive science, is that meanings are in the head. In other words, in cognitive semantics it is held that all human knowledge, knowledge handling, perception, and action are based on the conceptual system (Johnson, 1987; Lakoff, 1987). One of the basic principles is that meaning is often represented as geometric or spatial constructions. Major examples of these are the so-called image schemata proposed by Lakoff (1987) and Johnson (1987). Image schemata are simple, well-defined, 
and well structured images that are used over and over again to conceptualize structures in action, reflection, experience, and 'reality'. To take an example: the 'container schema' consists of the structural elements such as: interior-exteriorborder. Other typical examples of image schemata are: centre-periphery, up-down, directive (source-path-goal). Both Lakoff (1987) and Johnson (1987) contend that the image schemata are kinesthetic because they all are related to the human body and basic types of bodily action.

The image schemata thus reflect - in terms of schematic structures - that human experience and cognition are organized across different domains, i.e., they are a kind of depth semantics. One way of detecting which image schemata underlie a statement is to analyze the metaphor which is used.

The scientific research question is, however: does knowledge based on no-body information support or suppress knowledge of body information and vice versa?

With Virilio in mind, we may rephrase this question: does our fundamental use of no-body information suppress the development of our body and its senses and replace them with prostheses?

The value of opening up a path of this kind of cognitive semantic inquiry can only be shown through detailed case studies of phenomena that reveal something about the nature of human reason. Of course, we see the national ICT strategies as one such phenomenon.

The implication for the analysis of the effect of information and communication technology on society is that one should look for the image schemata re-presenting those metaphors that are central to the texts and to the political decisions and national strategies.

This method has been used to identify and count all the image schemata in the texts. The idea of a percentage of image schemata in the text as potential 'proof' of amnesia may be ill warranted. It is based purely on the intuitive knowledge that what is in the text is also in your mind and in your action.

Our first attempt at this investigation is depicted in column 5 in Table 1 . The image schemata of 'container' and 'directive' accounts for approximately $80 \%$ of the metaphors. We thus stipulate that most of the image schemata point to the tacit acceptance of the two first world views. And this only stresses the very strong limitations of sight (potential topographical amnesia), and of an only one way ahead scenario (potential historical amnesia).

This would not be so dangerous, if there were creative metaphors in the texts, as may be imagined from the third method of metaphorical analysis.

\section{METHOD THREE: METAPHORS IN AESTHETICS - LØGSTRUP'S THEORY}

Løgstrup states:

'Just because you replace a pale expression with a more lucid or graphical/pictorial, an abstract with a concrete, it is not said that you have a metaphor' (Løgstrup, 1976, p. 74. Our translation).

His reasoning behind this notion of metaphors is based on a theory of metaphors by Max Black (1954-55). He sees three different theories of metaphors: 
1. Substitution theory, which states that the metaphorical expression is equivalent to what is literally meant. Using a metaphor is for stylistic reasons. The metaphor is a decoration. A metaphor in this theory may also be necessary when no literal equivalent can be found which for example is the case for a triangle's 'legs'.

2. Comparison theory, where the metaphor presents an understood or implied analogy or equality, which is left to the reader or listener herself to realize in order to bring the metaphorical expression back to its literal equivalent. The metaphor is a concise parable. Black mentions Schopenhauer's statement that a mathematical proof is a 'mouse trap'. The implied meaning is that both a mathematical proof and a mouse trap offer a reward which is an illusion, and that seduces the victim and presents it with an unpleasant surprise.

3. The interaction theory, where the word, which is the focal point of our awareness, gets a new meaning by being put into a framework that is different from where it belongs. This new meaning is also different from the one it has in the domain where it belongs. Both the framework and the domains are given a different meaning. Furthermore, the new framework expands the meaning of the word in a way that cannot be substituted by a literal meaning.

4. As an example, a person may be described as being as wily as a fox, as sly as a snake or as gentle as a dove. This does not mean the fox is inherently wily, the snake is sly or the dove is gentle. But we want to pinpoint a person's wiliness, slyness and gentleness and we use the way a fox walks, the snake's slithering movement, and the looks of a dove as a pictorial expression of the person. In the jump from one domain to another, and one framework to another, the metaphorically used word gets a meaning it did not have before.

While the substitution and comparison metaphors can be translated into a nonmetaphorical expression, the interaction metaphor cannot. We may therefore conclude with Løgstrup that bringing two different words from two different domains together, in itself, does not make a metaphor.

Løgstrup goes even further and suggests that in order to have a metaphor:

- there must be strangeness between the two words and the two domains used

- the words must come from domains as far away from each other as possible

- the words must be as strange to each other as possible

- the words must create excitement in the expression

- the metaphors must create creativeness in the listener/reader

- the metaphor must be inexplicable, hiding its real meaning from direct translation.

For this third method of metaphorical analysis, we have derived two lessons from Løgstrup's way of looking at metaphors:

1. Find all those metaphors which fulfil Løgstrup's requirements. They must be there otherwise the texts on the information highway and information age are empty of feelings, meanings, and horizons. (This is the analysis preferred by Løgstrup.)

2. Find the tacit knowledge in the texts. (This is precisely what Lakoff's and Johnson's work on image schemata is all about) (Lakoff and Johnson, 1976).

Sadly enough we could only find 'skyway' in the American National Information Infrastructure (NII) report as a possible candidate for a metaphor in 
Løgstrup's sense. It is even questionable whether it is a metaphor in the American language, even though it seems so for a Dane trying to understand American.

\section{INSPIRATION OR AMNESIA BY METAPHORS}

Use of metaphors may thus create energy as well as stability in design. It may create potentials for the way we live and work. But it may certainly create very strong limits to our design of the way we may come to live and work on the information highway and in the information age.

Bani Shorter (1987, p. 118) puts it razor sharply:

'Human beings do not get their psychic energy from a model, but from myth, dream, and parable, which is the same as accepting, that man's most fundamental point of reference is something mystic, archetypal, and religious, more than it is something intellectual. Our intellect is very limited by our being human and by our human senses. Our lives do not have the goal of finding out how to be better men or women; they aim to be imitatio dei, and through initiation be invited to take part in the potential of the original myth.

Contrary to this models are created by humans which can be designed by what we already know and have seen. There are no metaphorical models; metaphor and myth are joined together with the mystical. It always contains something inexpressible and ineffable in precise terms; it remains unfinished, descriptive and familiar, but nevertheless unclear.'

This means that we need to use metaphors in Løgstrup's sense in order to get any psychic energy at all for our design. Metaphors are in fact also a gift, in the sense that they may fill the gaps which are always present in our communication and our rational design processes.

The lesson for theoreticians and practitioners in systems design may sound like this: stop building a surplus of Perceptrons, models and empirical data; imagine, create, and use inspiring metaphors.

At the same time, we have to admit that we will never be able to understand fully how system design really works, no matter how sophisticated our models may be. This insight was in fact put forward by Gödel, Wittgenstein, and Wiener more than fifty years ago, but the time may have come to bring this insight into our theories.

As mentioned above, there is only one metaphor in the texts which meet Løgstrup's requirements: skyway mentioned in the American NII report, p.23: 'Freeing up spectrum to create "skyways".' Whether this is really a conscious use of a metaphor is hard to say. It is hidden a long way back in the report. So we have to look at other spaces and at other times.

\section{AGES PAST AND WAYS OUT}

If our use of Lakoff's and Løgstrup's analysis is correct, we must look for better metaphors than the information highways in order to create visions for democracy, culture, and society in the information age. Global western amnesia is the problem, not globalization. The credo for sustainable development: Think Globally - Act 
Locally may come to have a new meaning if acting locally is guided by a literally narrow point of view and an extermination of our sense-apparatus.

We need better metaphors to live and work by if democracy, culture, and society are to be revolutionized in a radical fashion. But can metaphors be designed? No, not directly, but indirectly.

If the fundamental problem in democracy, culture, and society as a result of ICT strategies is the destruction of our fundamental categories and facilities to grasp them, we need to recover these categories and facilities from the only possible source we have in our hands, heads, and hearts: the power of aesthetics, ethics, epistemology, and religion embedded in a firm belief in spontaneity.

In our search for the design of better metaphors, we might look at the present, to the future or to the past. As we seem to have forgotten much of the past and as we seem to be blinded to the future by the present we can only turn to the forgotten, still not used, past. To our minds, two original candidates seem ready at hand as signposts from the past: Goethe and Kierkegaard. They both lost on their own battleground at that point in history. The time may have come for ICT people to look back in order to envision the future. We will just sketch our visions for our own recovery.

\section{RECOVERING FROM TOPOGRAPHICAL AMNESIA ON THE INFORMATION HIGHWAY}

Goethe was very interested in one of the areas of spatial-temporal interest for a new revolutionary look at ICT: our senses and our perceptions of colours.

Goethe's main idea is directly opposed to the Newtonian colour theory used in all national ICT strategies. Goethe's colour theory creates a very close relationship between the eye, the human body, and colours. He expressed this relation in an aphoristic form in 1805-06:

'The eye is the last and highest result of light in the organic body

The eye as creator of light creates all that which light may create by itself

The light renders all visible to the eye; the eye renders everything to the human being

The ear is speechless, the mouth is deaf, but the eye senses and speaks. In that it mirrors the world from outside, the human being from inside

The totality of inner and outer is completed through the eye.'

(Our translation from Goethe, Färgläre, Swedish edition, 1976.)

When Goethe says that colour is a child of light and dark, he complements natural science thinking with a philosophical and poetic dimension. Light is symbolic for Goethe. He considers light as the most simple and most homogenous phenomenon in the world. It cannot be divided, split or refracted.

Newton analyzes and experiments until he reaches measurable light [particles] splitting and refracting. He represents the objective, measuring, natural science way of thinking - positivism.

Goethe's interest is in describing immeasurable light (the homogenous - the indivisible - the pure - the symbolic light). He thinks holistically. He expands natural science thinking to encompass the investigation of the physiology of senses 
- how human beings experience colours. Outer observations leads to inner observations. Goethe's view leads to psychology.

That we have to act with qualitatively different ways of looking at the world is illustrated by the following citations from a conversation between Eckermann and Goethe. Goethe says:

'I disagreed with Newton's theory of light and colour, when I realized that it was a delusion. I experienced the light in its purity and truth and I had it as a vocation to fight for. But the other side strives in all seriousness to darken the light, as they postulated that shadow is part of light. It sounds meaningless when I say it this way, but the case is like this: They said that colours are something thoroughly shadowed and shadowy. They are the light itself, they are light beams, which are refracted in different ways.

"I'm sorry for many a good student," Goethe said, "it can be completely indifferent to me as my colour theory is as old as the world and it will survive and cannot be denied and pushed aside in the long run."

For Newton and natural science thinking, light is an intellectual, craftsmanlike challenge. For Goethe it is in addition a deep mental and spiritual matter.'

(Our translation from Schmidt, 1993 and Eckermann, 1963.)

We have two colour theories: Newton's and Goethe's. However, the only one used so far on the information highway and in the information age is Newton's. Should this also be the only colour theory used in the future? If so, we will not only get rid of purple and crimson, the highest red colours, which curiously enough do not show up when Newton's light is refracted, but we will also get rid of our eyes as sadly envisioned by Virilio. The study and use of Goethe's colour theory is necessary on our way to recovering from topographical amnesia ${ }^{4}$.

\section{RECOVERING FROM HISTORICAL AMNESIA}

The Danish philosopher, Søren Kierkegaard, on the other hand, has perhaps taken the most radical view on human choice and existence in history in his search for a way of personal Christian life in coexistence with other human beings and nature.

We live in stages in existence and coexistence, Kierkegaard tells us in Stages on the Way to Life. And we make pauses in what he calls confinie. He envisioned the following potential stages ${ }^{5}$ and confinie in a person's historical existence:

- spontaneous stage; erotic, sensualism, love

- curiosity as confinie; the heroic mood

- aesthetic stage; beauty and pleasure, the individual, courage to act, philia

- irony confinie; distance to the world and oneself, purification

- ethical stage; good, the collective, agape

- humour confinie; hope for our finite life

- religious stage; belief, the mythic, the mystic, caritas

- clarity as confinie; hope for our infinite life

- epistemology; truth, wisdom

But Kierkegaard also tells us that we cannot communicate on serious matters in a direct way. We must also use an indirect message. And we cannot separate the message from the messenger. He insists that the only possibility is to let every man speak for himself, make his own choices, and formulate his own existence and 
coexistence. His work is perhaps the most generic and fully developed theory of communication between humans across different world views and cultures.

However, on the information highway and in the information age, it seems that personal choice and communication must be fixed at the first two stages and the first confinie in order for us all to be entertained and kept as prisoner without any personal historical development possible. The national strategies as well as the credos of the information highway and information age do not allow for personal collective choices to wander beyond the aesthetic stage of pleasure.

Imagine working and living in all these stages and confinies! Wouldn't it be marvellous, even if you have to choose once in a while.

\section{CONCLUSION}

Our way of writing has been like meandering or like a debate in the agora. However, any meandering and any debate must come to a pause, and ask: was it worthwhile or just a waste of time? We do not yet know exactly.

There is still much to said, heard, seen, and experienced in the globalization of the world. Maybe we are part of it, maybe not. Maybe globalization in itself is just another means of domination. Or as expressed by Janis Joplin a long time ago: 'Freedom [in the Global World] is just another word for nothing left to lose'.

In the words of Churchman at the end of his The Design of Inquiring Systems, the Latin concludere means 'to shut up together'. And yet - setting the agora for the next debate:

Topos and ingegno are, for Aristotle, those parts of rhetoric which are about proofs and inventiveness. Topos is based on so-called enthymemes, which are differentiated from strict scientific proofs by building on implicit understanding, assumptions (doxai), conjectures, probabilities, and everything that is more or less commonly recognized as part of the public debate. When a speaker must convince an audience on the righteousness of a decision of a political and juridical nature it does not help to use arguments and viewpoints which are unfamiliar or unknown to the audience. On the contrary, the speaker must build the arguments on ideas on which most people agree - what is clever policy, what is suitable morality, and what is a correct line of action. Aristotle calls such assumptions topoi which means places, namely those places which the rhetorical argumentation may take as starting points. The Romans called them loci commune (common places), and it is exactly such common places that we have to find in order to exist democratically and to coexist across values, opinions, cultures, regions, and life-forms. But ingegno (in Latin, ingenium) is the creative part of rhetoric. It brings new insights and new combinations to the debate and it is based on a poetic, unconscious, artistic creativity.

A very conscious poetic and political choice of metaphors might have been behind the terms information highway and information age. 


\section{REFERENCES}

The National Information Infrastructure - Agenda for Action, 1993.

European Round Table of Industrialists: Building The Information Highways to Reengineer Europe A Message from Industrial Users, 1994.

Europe and the Global Information Society - Recommendations to the European Council, 1994.

Berleur, J. (this volume) Culture and democracy revisited in the global information society: Summary of a position paper.

Berleur, J. and Whitehouse, D. (this volume) Recommendation: From sand, through silver, to gold plates.

Black, M.: Metaphor, Proceedings of the Aristotelian Society, Vol. LV, 1954-55.

Churchman, C.W.: Philosophical Speculations on Systems Design, Omega, Vol. 2, no. 4, 1976.

Churchman, C.W.: The Design of Inquiring Systems, Basic Books, 1971.

Churchman, C.W.: The Systems Approach and Its Enemies, Basic Books, 1982.

Eckermann, J.P.: Samtaler med Goethe, Gyldendal, 1963 (in Danish, org. German: Gespräche mit Goethe in den letzen Jahren seines Lebens, 1836-1848).

Goethe, J.W.: Goethes Färgläre, Kosmos Förlag, Järna, 1976 (in Swedish, org. German 1791 - 1832).

Holm-Pedersen, J. and Rasmussen, L.B.: Geographical Information Systems for Sustainable Development, paper presented to Conference on GIS in Business, Madrid, 1995.

Jantsch, E.: The Design for Evolution, Brazillier, 1975.

Jantsch, E.: Self-Organizing Universe, Addison-Wesley, 1979.

Johnson, M.: The Body in the Mind, University of Chicago Press, 1987.

Judge, A. J.: Metaphors in Concepts of the Future, Futures, Vol. 25, December 1993.

Kendall, J. E. and Kendall, K. E.: Metaphors and Methodologies: Living Beyond the Systems Machine, MIS Quarterly, Vol. 17, no.2, June 1993.

Kierkegaard, S.: Stages on The Way of Life, Copenhagen, 1962 (in Danish, org. 1846).

Krarup, G.: Cognitive Aspects as Design Criteria for Human-Computer Interface, Paper presented to Human Factors in Organizational Design and Management - IV ODAM Conference, Stockholm, 1994.

Krarup, G. and Rasmussen, L.B.: Curriculum for Sustainable Development, Paper presented to the TC-3/TC-9 Conference on ICT in Education, Israel, 1996.

Lakoff, G. and Johnson, M.: Metaphors We Live By, Chicago University Press, 1976.

Lakoff, G.: Women, Fire, and Dangerous Things, Chicago, 1987.

Løgstrup, K.E.: Vidde og Pragnans, Copenhagen, 1976 (in Danish).

Morgan, G.: Images of Organizations, SAGE publ., 1986.

Rasmussen, L.B.: Political Choice of Metaphors in Organizational Design, Paper presented to Human Factors in Organizational Design and Management - IV ODAM Conference, Stockholm, 1994.

Rasmussen, L.B.: Alternative World Views in Systems Design, Working Paper, Inst. of Informatics and Management Accounting, Copenhagen Business School, 1995 (in Danish).

Rasmussen, L.B.: Alternative Models for Project Management, Working Paper, Folkuniversitetet, Malmø, 1996 (in Danish).

Schmidt, L.: Farven og Lyset - Studier i Goethes Farveleere, Klematis, Aalborg 1993 (in Danish).

Shorter, B.: An Image Darkly Forming, Routledge, Kegan, Paul, 1987.

Singer, E. A.: Mind as Behavior, R.G.Adams \& Co., 1924.

Singer, E. A.: In Search of a Way of Life, Columbia University Press, 1948.

Singer, E. A.: Experience and Reflection, Columbia University Press, 1959 (ed.: C.W. Churchman).

Virilio, P.: La Machine de Vision, Éditions Galilée, 1988. (Danish edition: Synsmaskinen, København, 1989).

1 We emphasize that this article is exploratory and conjectural in order to provoke discussion as intended by the call for papers (Berleur, this volume). We hope it is a sand paper in the sense of being able to suggest further topics, and erasing those taken to be unfruitful (Berleur and Whitehouse, this volume). We wish to thank the referees for very useful comments.

2 Jules Romains: La vision extra-rétinnienne et le sens paroptique, Paris, 1920. This future-oriented 
book was revised in 1964: 'Experiments with that vision which is situated outside the retina, show us, that some kind of damage in the eye (strabismus, for example) provokes in the person a refusal from the consciousness of the image even though the eye has retained its abilities: the image is created, but consciousness refuses it with ever increasing eagerness, even to the point of blindness' (cited from Virilio, Danish version).

3 It is our hypothesis that this kind of investigation must be carried out in an indirect manner as we cannot grasp what is happening to our fundamental categories in a direct way. The explanation for this hypothesis will, hopefully, be obvious through the discussion, especially through cognitive semantics.

4 Anyone studying colours and colour theory must know the implications of the question: what created colours, the eye or the colours? The debate is there, but not in the creation of colours through as many pixels as possible. Quantity in itself will never catch up with quality.

5 The term 'stages' must not be taken as one step after the other. Stages are rather potential standpoints or world views through which we may exist and coexist. 